ISSN 0103-9954

\title{
DIAGNÓSTICO DOS VIVEIROS MUNICIPAIS NO ESTADO DE MINAS GERAIS ${ }^{1}$
}

\section{DIAGNOSES OF NURSERIES IN MINAS GERAIS STATE}

Elzimar de Oliveira Gonçalves ${ }^{2}$ Haroldo Nogueira de Paiva ${ }^{3}$

Wantuelfer Gonçalves ${ }^{3}$ Laércio Antônio Gonçalves Jacovine ${ }^{3}$

\section{RESUMO}

Com o objetivo de fazer um diagnóstico dos viveiros municipais do Estado de Minas Gerais, foi enviado um questionário a todos os seus 853 municípios, contendo perguntas sobre infra-estrutura, tamanho, existência de responsável técnico, qualificação e treinamento de viveiristas, técnicas utilizadas na propagação das plantas, sistema de irrigação, dentre outros aspectos. Pelos resultados, obtidos nas 270 respostas, foi constatado que grande parte dos municípios estudados não possui viveiros para produção de mudas, o que permite inferir que elas são adquiridas de terceiros ou que não está havendo arborização nas ruas. Nos municípios que possuem viveiros constatou-se que a infra-estrutura verificada é insuficiente e que não há profissionais de nível técnico em sua maioria. Além disso, o treinamento de funcionários poderia ser mais efetivo, uma vez que eles são em grande parte, fixos, embora com baixa escolaridade. Observou-se também que as plantas são propagadas basicamente por sementes e estacas, tendo como finalidade a arborização urbana e a recuperação de áreas degradadas e de matas ciliares, e que são destinadas, principalmente, para doação. Na maioria dos municípios os conhecimentos acerca dos tratos culturais necessários à produção de mudas com características desejáveis à arborização urbana são incipientes.

Palavras-chave: viveiros; diagnóstico; produção de mudas; arborização urbana.

\section{ABSTRACT}

With the objective producing a diagnosis of the municipality public nurseries in the state of Minas Gerais, there were sent a questionnaire to all 853 cities, inquery questioning the of infrastructure, size, existence of a technician, qualification and training of workers, techniques used in the propagation of the plants, irrigation system, amongs other aspects. According to the results it was evidenced that the major part of the studied cities does not have nurseries for production of seedlings, what led to the conclusion that they are acquired of third part or tree in the streets are not being planted. The observed infrastructure is insufficient, and there are not professional technicians in its majority; moreover, the training of employees could be more effective, since they are to a large extent, employees although with low scholarly. The plants are basically propagated by seeds and cuttings, have as purpose the urban landscape, the recovery of degraded areas and riparian forest, and are destined, mainly, to donation. In the majority of the cities the knowledge concerning the necessary cultural treatments for the production of seedling with desirable characteristics to the urban landscape are incipient.

Key words: nurseries; diagnoses; seedlings production; landscape.

\section{INTRODUÇÃO}

A presença de florestas, no meio rural, adiciona valores positivos para a comunidade em geral, por proporcionar diversos benefícios como proteção do solo, manutenção da biodiversidade, alimentação da fauna, dentre outros.

Nos centros urbanos, a presença de florestas urbanas e a arborização urbana são responsáveis pela melhoria da qualidade de vida da população sob diversos aspectos.

Em áreas rurais, têm sido adotados na atualidade plantios florestais com as espécies eucalipto e pinus em áreas de pequenos produtores, exercendo um aspecto social muito importante em termos de utilização de mão-de-obra e fonte alternativa de renda.

1. Parte da dissertação, do primeiro autor, apresentada à Universidade Federal de Viçosa. Trabalho financiado pela Fundação O Boticário de Proteção à Natureza.

2. Engenheira Florestal, MSc., Departamento de Engenharia Florestal, Universidade Federal de Viçosa, CEP 36571000, Viçosa (MG). Bolsista do CNPq.

3. Professor do Departamento de Engenharia Florestal - Universidade Federal de Viçosa. 36571-000 Viçosa-MG.

Recebido para publicação em 13/03/2003 e aceito em 10/09/2004. 
Outro aspecto que deve ser levado em consideração é que, com o intenso desmatamento ocorrido no passado, áreas que deveriam abrigar florestas, conforme exigência do código florestal, como topos de morro e matas ciliares, foram destinadas a outros usos, muitas vezes inadequados, trazendo sérios prejuízos ao ecossistema como um todo, tornando-se necessária sua recuperação com o plantio de espécies nativas da região.

A produção de mudas e seu manejo adequado tornam-se, portanto de extrema importância, uma vez que é através dessas mudas que se terá uma floresta no futuro, seja qual for a finalidade. Tal afirmativa reforça a importância da instalação de viveiros com infra-estrutura adequada e do gerenciamento com profissionais qualificados.

Uma infra-estrutura básica para suporte da produção deve conter: escritório; banheiros (feminino e masculino); cozinha ou cantina; almoxarifado e área coberta em cima e dos lados para o trabalho em dias chuvosos; cômodo para guardar ferramentas; galpão para armazenamento de recipientes e adubos; e galpão para armazenamento de agrotóxico. E, ainda, dependendo do porte, do grau de sofisticação e da especificidade do viveiro, poderá ter estufas de enraizamento de estacas; casa de sombra para semeadura e posterior repicagem, ou aclimatação de espécies; pequeno laboratório para quebra de dormência em sementes, pesagem de adubos e defensivos e preparo de hormônios; laboratório para micropropagação; sementeiras, caixas de enraizamento; e sistema de irrigação (IEF, 2000).

O objetivo desse trabalho foi fazer um diagnóstico dos viveiros municipais do estado de Minas Gerais, avaliando sua infra-estrutura, tamanho, existência de responsável técnico, qualificação e treinamento de viveiristas, técnicas utilizadas na propagação das plantas, sistema de irrigação, além de outros aspectos.

\section{MATERIAL E MÉTODOS}

O diagnóstico foi feito por meio do questionário a seguir, enviado a todos os 853 municípios do Estado de Minas Gerais em setembro de 2001.

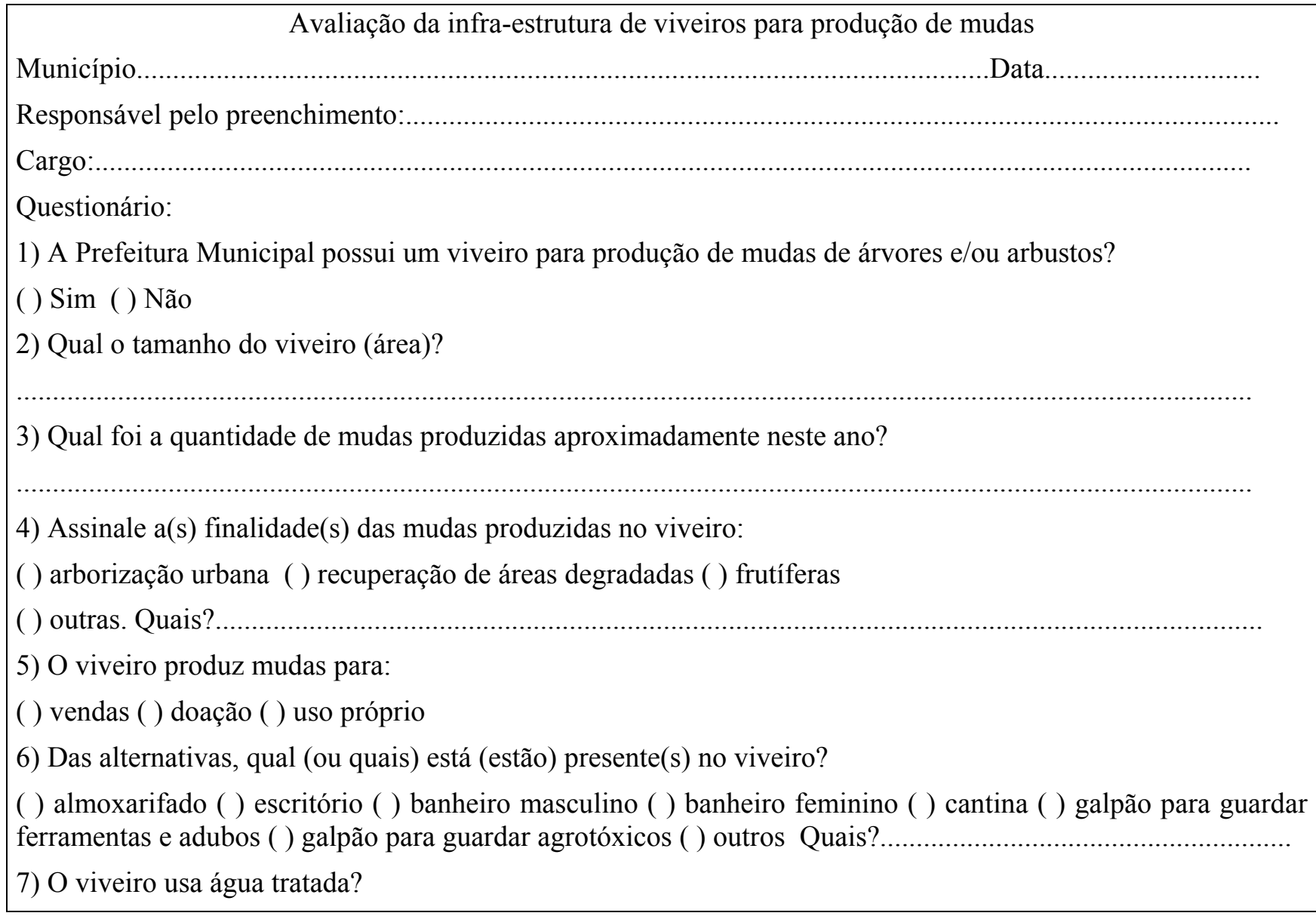




\begin{tabular}{|c|}
\hline ( ) Sim ( ) Não \\
\hline 8) Quais os principais recipientes utilizados na produção das mudas? \\
\hline ( ) sacolas plásticas ( ) tubetes ( ) latas de 20L ( ) outros Quais? \\
\hline 9) Existe responsável técnico? \\
\hline ( ) Sim ( ) Não \\
\hline 10) Se existe responsável técnico, qual a sua qualificação? \\
\hline ( ) Técnico agrícola ( ) Engenheiro florestal ( ) Engenheiro agrônomo ( ) Outro Qual?..... \\
\hline 11) Se não existe responsável técnico, o viveiro recebe assistência técnica externa? \\
\hline ( ) Não ( ) Sim De quem?.......................................................... \\
\hline 12) Há quanto tempo o viveirista responsável pelo viveiro exerce essa atividade? \\
\hline 13) Qual é o grau de escolaridade do viveirista? \\
\hline 14) O viveirista recebeu ou recebe treinamento periodicamente? \\
\hline ( ) Sim ( ) Não Caso afirmativo, de quem?............. \\
\hline 15) Qual é o número de funcionários do viveiro? \\
\hline 16) Os operários que fazem os tratos culturais são? \\
\hline 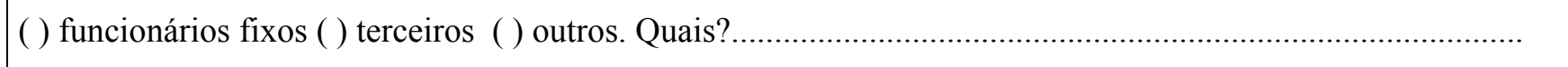 \\
\hline $\begin{array}{l}\text { 17) Em relação aos funcionários que fazem os tratos culturais no viveiro, quantos se encaixam nas seguintes } \\
\text { situações? }\end{array}$ \\
\hline ( ) $1^{\circ}$ grau incompleto ( ) $1^{\circ}$ grau completo ( ) $2^{\circ}$ grau incompleto ( ) $2^{\circ}$ grau completo \\
\hline 18) Qual a média de idade desses funcionários? (colocar a variação) \\
\hline 19) Quais as técnicas utilizadas na propagação das mudas? \\
\hline ( ) estaquia ( ) sementes ( ) outros. Quais?........................... \\
\hline 20) Como é feita a irrigação? \\
\hline 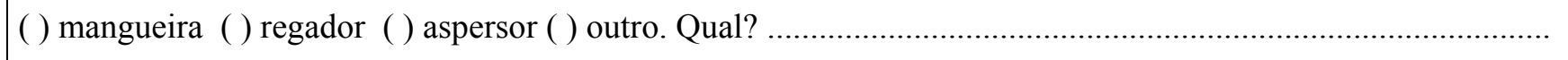 \\
\hline $\begin{array}{l}\text { 21) Quais critérios são considerados importantes para a expedição de mudas que serão usadas na arborização } \\
\text { urbana? }\end{array}$ \\
\hline $\begin{array}{l}\text { ( ) diâmetro mínimo de } 3 \mathrm{~cm} \text { ( ) altura mínima para inserção do primeiro galho de } 1,80 \mathrm{~m} \mathrm{(} \mathrm{)} \mathrm{número} \mathrm{de} \\
\text { pernadas igual a } 3 \text { ( ) perpendicularidade de } 90^{\circ} \text { em relação ao nível do solo ( ) ausência de doenças ( ) ausência } \\
\text { de deficiência nutricional ( ) ausência de plantas daninhas ( ) tronco reto, sem tortuosidade. }\end{array}$ \\
\hline
\end{tabular}

De posse dos questionários que retornaram (270), procedeu-se à compilação dos dados, que foram transformados em percentuais. Posteriormente, foram gerados gráficos de barras. 


\section{RESULTADOS E DISCUSSÃO}

\section{Caracterização dos municípios que enviaram respostas}

Dos 853 municípios, 270 responderam ao questionário, totalizando um percentual de 31,65\%. Destes 270, 46,47\% possuem viveiros, representando 124 municípios. Winters et al.(1992), em um diagnóstico similar, porém feito em duas etapas e com finalidade de manutenção da arborização feito com municípios do estado de São Paulo, obteve 51,57\% de respostas, dos quais 34,57\% possuíam viveiro.

A Tabela 1 mostra, que a maioria (67,04\%) dos municípios que enviaram respostas ao questionário possui até dez mil habitantes residindo nas cidades, ou seja, são de pequeno porte.

Em termos de população, os municípios que enviaram respostas ao questionário, segundo dados obtidos no IBGE (2002), representam 53,7\% da população urbana do Estado.

TABELA 1: Relação da porcentagem de cidades e população urbana existente nos municípios que enviaram respostas ao questionário.

TABLE 1: Relation of the percentage of cities and existing urban population in the cities answered the questionnaire.

\begin{tabular}{l|c|c|c}
\hline $\begin{array}{l}\text { População Urbana } \\
\text { (habitantes) }\end{array}$ & $\begin{array}{c}\text { Porcentagem de } \\
\text { Municípios }\end{array}$ & $\begin{array}{c}\text { População Urbana } \\
\text { (habitantes) }\end{array}$ & $\begin{array}{c}\text { Porcentagem de } \\
\text { Municípios }\end{array}$ \\
\hline Até 2.000 & 16,30 & 50.001 a 100.000 & 6,67 \\
2.001 a 5.000 & 30,74 & 100.001 a 200.000 & 1,11 \\
5.001 a 10.000 & 20,00 & 200.001 a 300.000 & 1,48 \\
10.001 a 20.000 & 15,56 & 300.001 a 500.000 & 0,74 \\
20.001 a 50.000 & 7,04 & Mais de 500.000 & 0,37 \\
\hline
\end{tabular}

\section{Análise do porte dos viveiros}

\section{Tamanho}

Existe grande variação no tamanho dos viveiros, com 57,6\% deles ocupando áreas de até $3000 \mathrm{~m}^{2}$, conforme se observa na Figura 1.

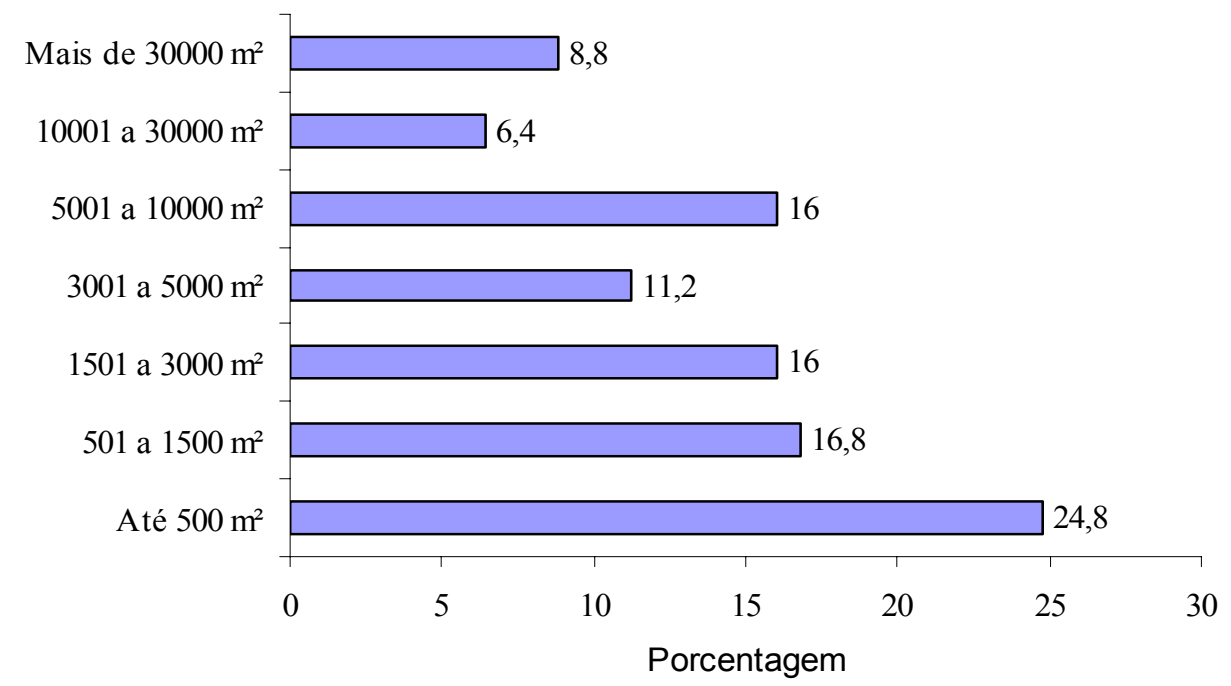

FIGURA 1: Distribuição percentual dos viveiros dos municípios do Estado de Minas Gerais em relação ao seu tamanho.

FIGURE 1: Percentile distribution of nurseries in the cities of Minas Gerais State in relation to its size.

Também foram verificados viveiros com grandes áreas, com mais de 3 ha, os quais são encontrados em cidades de maior porte, com grande demanda de mudas. 


\section{Quantidade de mudas produzidas}

Verifica-se, pela Figura 2, que a grande maioria dos viveiros públicos municipais $(55,26 \%)$ produz até trinta mil mudas por ano, mas também foram verificados aqueles com capacidade para produzir mais de 100 mil mudas por ano. Cerca de 10,53\% deles não produziram nenhuma muda, pois estavam desativados em 2000, período de estudo deste trabalho.

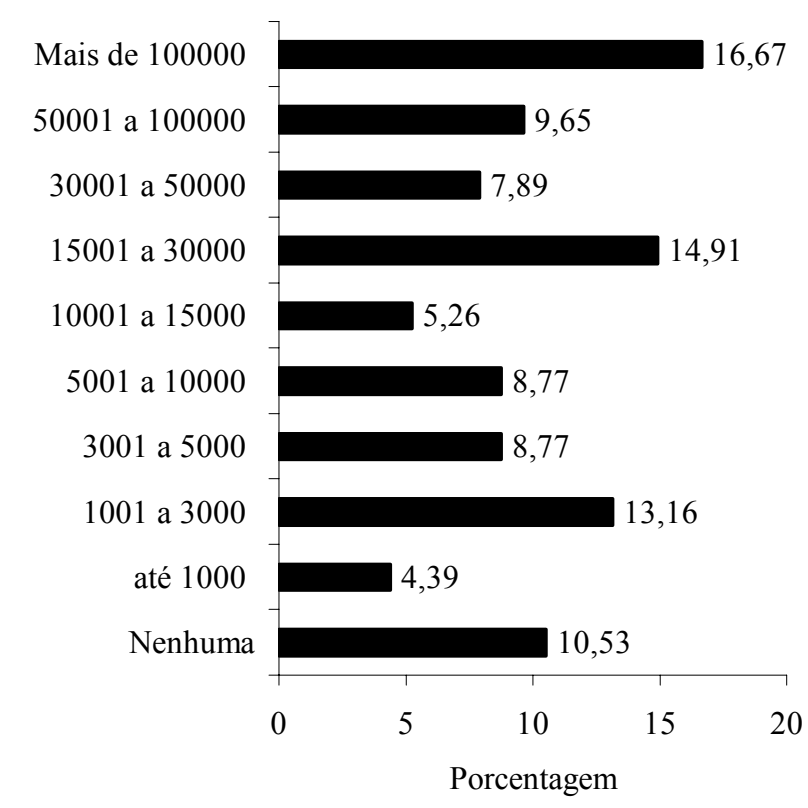

FIGURA 2: Percentual relativo à quantidade de mudas produzidas nos viveiros dos municípios do Estado de Minas Gerais em setembro de 2001.

FIGURE 2: Relative percentage of the amount of seedlings produced in the nurseries of the cities of Minas Gerais State.

\section{Número de funcionários}

Pela Figura 3, observa-se que a maioria dos viveiros (84,35\%) possui de um a cinco funcionários, o sugerindo que os municípios são de pequeno porte e têm baixa demanda por mudas.

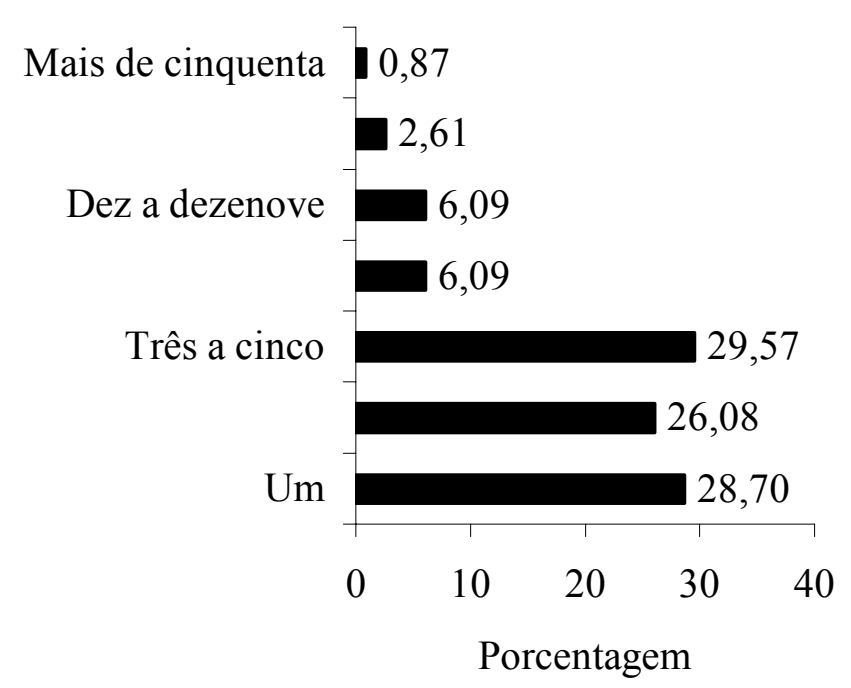

FIGURA 3: Número de funcionários que trabalham nos viveiros dos municípios do Estado de Minas Gerais. FIGURE 3: Number of employees who work in the nurseries of cities of Minas Gerais State. 


\section{Análise da produção de mudas}

\section{Finalidade das mudas produzidas}

Pode-se observar, através da Figura 4, que a grande maioria dos municípios $(83,87 \%)$ produz mudas com a finalidade de arborização urbana.

A produção de mudas de plantas ornamentais está presente em $20,16 \%$ dos viveiros, sendo uma percentagem bem inferior à da produção para arborização urbana. Isso se deve ao fato de a implantação e a manutenção de jardins serem bem mais onerosas em relação às árvores plantadas nas ruas.

O que chama a atenção nas respostas é a produção de mudas para recuperação de áreas degradadas, matas ciliares e proteção de nascentes, demonstrando que pode estar havendo maior consciência ambiental. Além disso e o plantio de mudas para essas finalidades é, de certa forma, uma atividade menos onerosa.

$\mathrm{Na}$ opção outras finalidades, encontram-se viveiros que produzem mudas de café, teca, pinus, eucalipto e mamão.

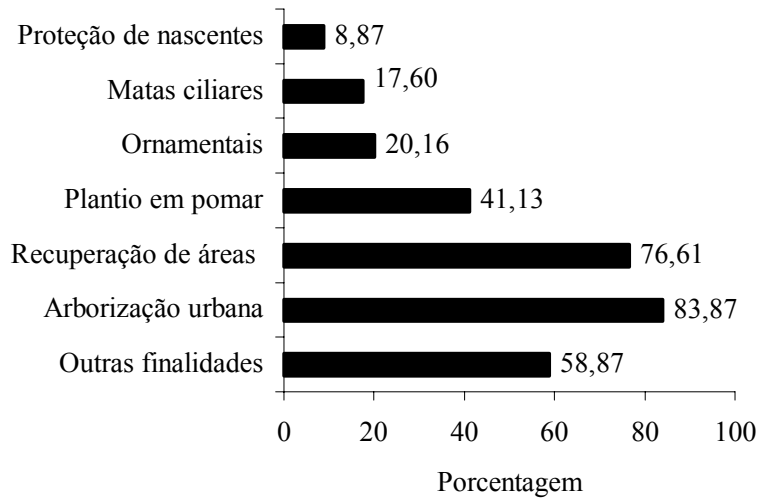

FIGURA 4: Finalidade das mudas produzidas nos viveiros dos municípios do Estado de Minas Gerais.

FIGURE 4: Purpose of the seedlings produced in the nurseries of cities of Minas Gerais State.

\section{Destino das mudas produzidas}

Verifica-se, pela análise da Figura 5, que a maioria dos municípios $(64,06 \%)$ produz mudas para doação e uso próprio, e só para doação, não constituindo o viveiro, portanto, uma fonte de renda para os municípios, uma vez que apenas $1,56 \%$ dos viveiros produz mudas exclusivamente para venda.

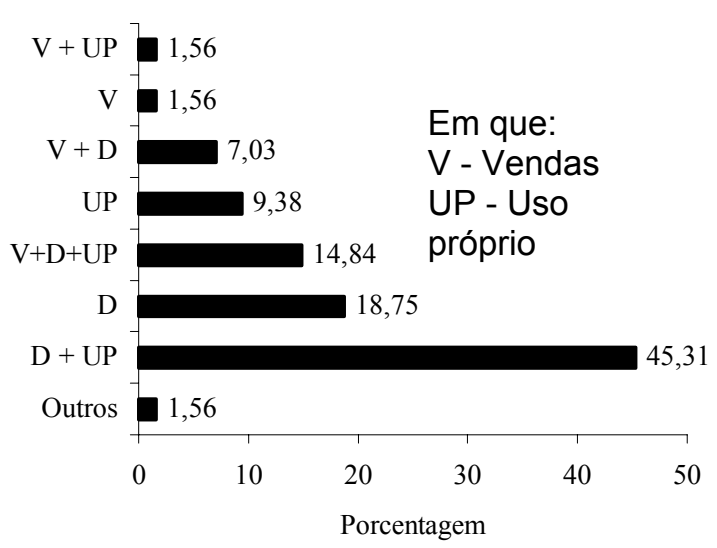

FIGURA 5: Destino das mudas produzidas nos viveiros dos municípios do Estado de Minas Gerais.

FIGURE 5: Destination of the seedlings produced in the nurseries of cities of Minas Gerais State. 
A produção de mudas para uso próprio em grandes cidades, na maioria das vezes, é plenamente justificável para plantas ornamentais e arborização urbana, pois a aquisição destas de terceiros pode ser bastante onerosa, em virtude da quantidade requerida.

Na opção outros, encontram-se os viveiros que vendem as suas mudas a preço de custo.

\section{Propagação das plantas}

Os conhecimentos sobre produção de mudas com o uso de estaquia, miniestaquia e até micropropagação, embora já estejam bem avançados em empresas privadas, ainda não estão sendo empregados nos viveiros públicos dos municípios de Minas Gerais, mesmos naqueles que produzem mudas só para reflorestamento. A utilização dessas técnicas seria interessante, pois permitiria produzir clones mais bem adaptados ao local.

Uma provável explicação da não utilização dessas técnicas seria o custo e a falta de conhecimento técnico. Isso faz com que as sementes sejam as mais utilizadas, devido à facilidade de aquisição e ao menor custo.

A estaquia é utilizada principalmente na propagação de plantas ornamentais e de espécies que estão sendo usadas na arborização urbana, como astrapéia (Dombeya wallichii) e hibisco (Hibiscus sp).

A enxertia empregada em $6,3 \%$ dos viveiros públicos municipais é justificável para espécies que tenham dificuldade de propagação por sementes ou estacas e também quando se quer aproveitar características de determinada espécie, como resistência, produtividade, dentre outras.

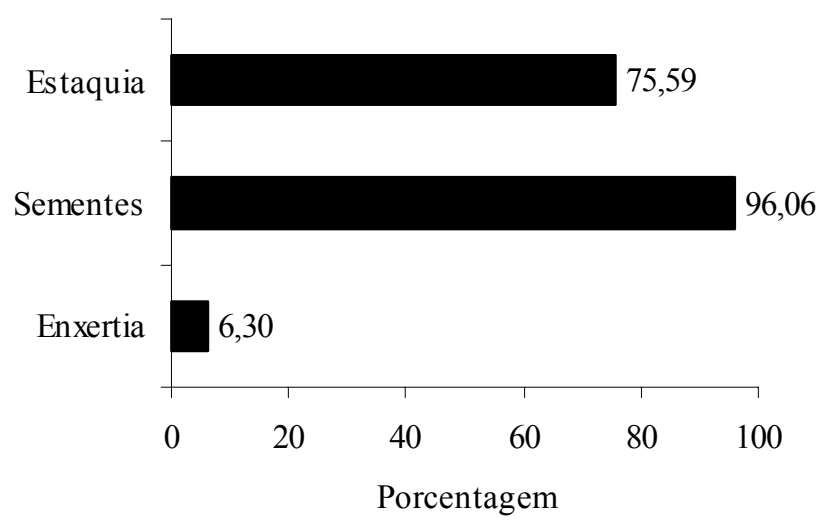

FIGURA 6: Métodos de propagação utilizadas nos viveiros dos municípios do Estado de Minas Gerais. FIGURE 6: Methods used for the propagation in the nurseries of cities of Minas Gerais State.

\section{Infra-estrutura dos viveiros}

É mostrado, na Figura 7, que os viveiros, em sua grande maioria, não possuem infra-estrutura adequada. A mais comum, em $85,84 \%$ dos viveiros, é o galpão para guardar ferramentas e adubos. Apenas $28,32 \%$ dos viveiros possuem local específico para guardar agrotóxicos. Isso mostra a falta de preocupação ou de conhecimento em armazenar esses defensivos de forma correta e segura. Sugere-se que sejam armazenados juntamente com ferramentas e adubos. Foram citados outros tipos de infra-estruturas como, por exemplo, bibliotecas, salas para ministrar cursos, casa de vegetação, porém presentes em apenas $8,85 \%$ dos viveiros analisados.

Embora tenha que se considerar o porte do viveiro para a existência de estruturas adequadas, estruturas básicas como banheiros, por exemplo, não estão presentes em todos eles; há ainda viveiros sem nenhuma infra-estrutura. Portanto, os funcionários não possuem condições mínimas para trabalhar, o que, provavelmente, pode levar à insatisfação e a um baixo rendimento nas atividades. 


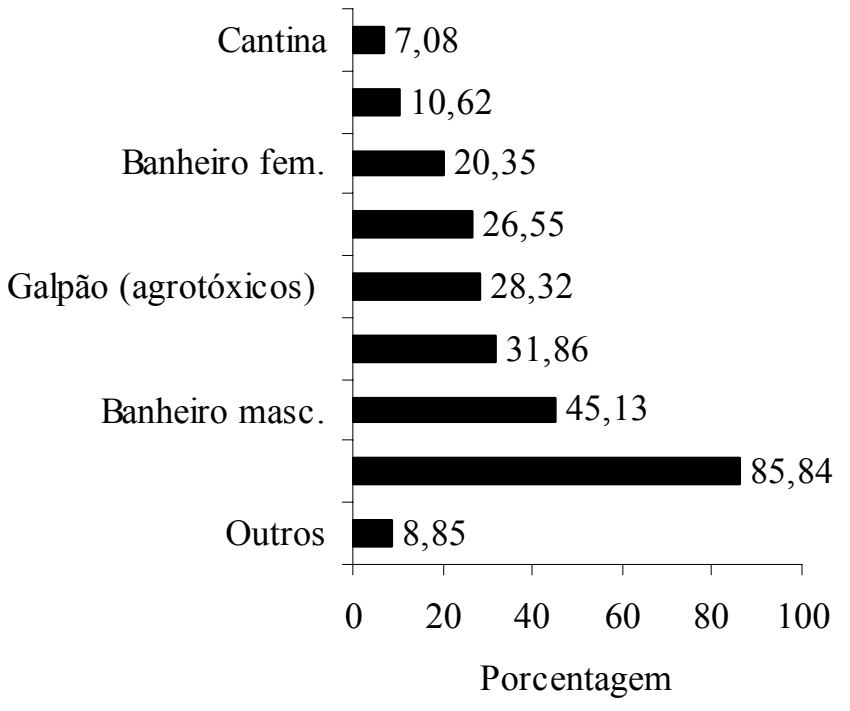

FIGURA 7: Infra-estrutura dos viveiros dos municípios do Estado de Minas Gerais.

FIGURE 7: Infrastructure of the nurseries of cities of Minas Gerais State.

\section{Qualidade da água e irrigação}

Dos municípios avaliados, $60,66 \%$ usam água sem tratamento, ao passo que quatro responderam que a água é proveniente de poço artesiano.

A grande maioria dos viveiros utiliza a irrigação por aspersão; no entanto, $22,6 \%$ dos viveiros públicos municipais usam somente mangueiras e regadores, indicando que nestes municípios a irrigação é bem rudimentar. Na opção outros, encontram-se os microaspersores (Figura 8).

A água é um fator de extrema importância em um viveiro, o qual não é aconselhável que seja implantado onde o suprimento desse fator seja insatisfatório. No entanto, a água deverá ser de qualidade, devendo-se tomar o cuidado para que não esteja contaminada, principalmente se provém de rios em cujas imediações existam fábricas ou indústrias que joguem neles dejetos com elevados teores de sódio e metais pesados, (Paiva e Gonçalves, 2001) ou de baixadas com altos teores de alumínio, ferro e manganês (Paiva e Gomes, 2000).

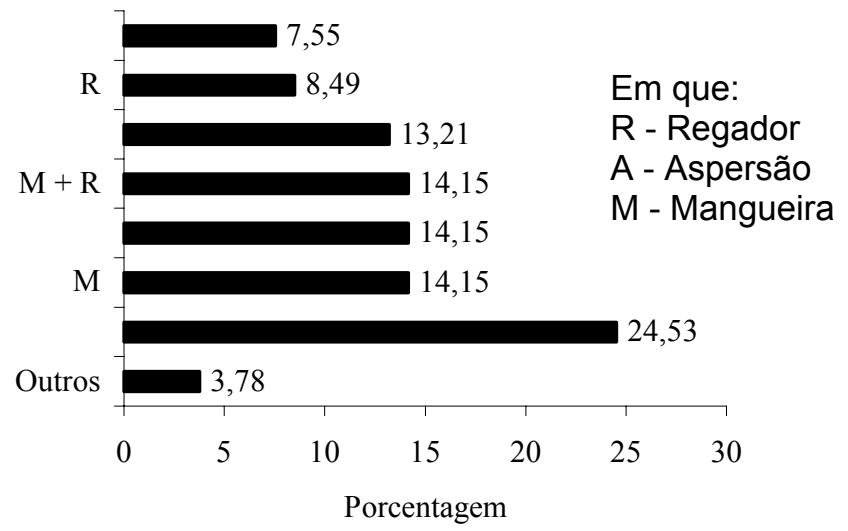

FIGURA 8: Métodos de irrigação adotados nos viveiros dos municípios do Estado de Minas Gerais.

FIGURE 8: Methods of irrigation in the nurseries of cities of Minas Gerais State. 


\section{Recipientes utilizados}

Existe grande variedade de recipientes disponível no mercado. A escolha de qual deles usar vai depender de fatores como custo, finalidade e qualidade das mudas.

Embora nas empresas do setor florestal o tubete seja o recipiente mais utilizado, nos viveiros públicos municipais do Estado de Minas Gerais, foi verificado que os mais usados são os sacos plásticos (Figura 9). Um fator que pode determinar esse uso é o tamanho da muda, como é o caso daquelas usadas na arborização urbana, que necessitam de um volume de substrato entre 15 e 20 litros aproximadamente. Além disso, sua grande disponibilidade no mercado e o menor preço contribuem para que sejam largamente utilizados.

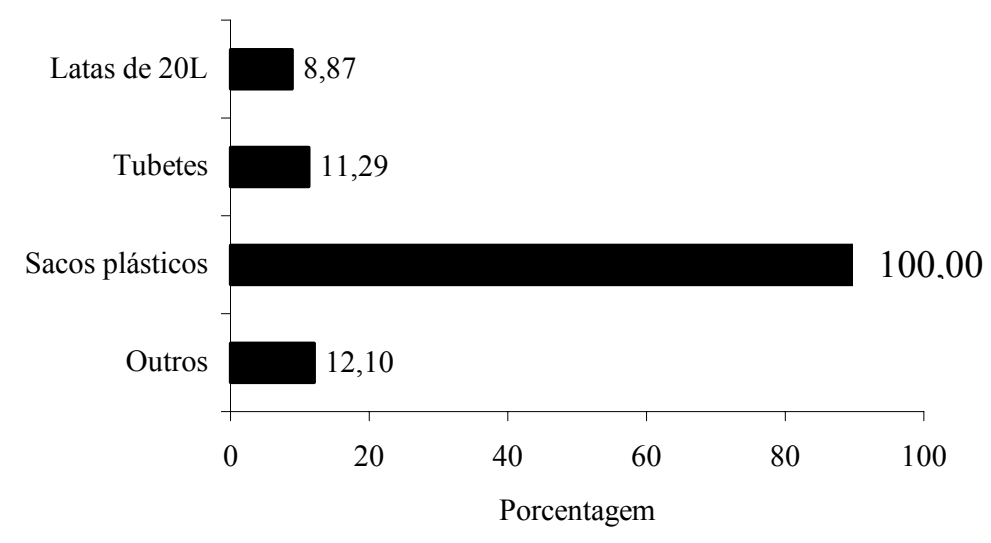

FIGURA 9: Tipos de recipiente utilizados nos viveiros dos municípios do Estado de Minas Gerais. FIGURE 9: Types of container used in the nurseries of cities of Minas Gerais State.

$\mathrm{Na}$ opção outros, foram citadas embalagens alternativas, como copos descartáveis, garrafas pet e até sacos plásticos usados para embalagem de arroz, feijão e açúcar.

A utilização desses materiais alternativos é interessante porque permite a reciclagem daqueles que seriam descartados, além de reduzir os custos com aquisição de embalagens.

\section{Presença e qualificação de responsável técnico}

Dos 124 municípios que possuem viveiros e que enviaram respostas ao questionário, 21 não têm responsáveis técnicos, e destes, apenas 13 recebem assistência técnica externa, sendo os principais órgãos que prestam esse serviço o Instituto Estadual de Florestas (IEF) e a Empresa de Assistência Técnica e Extensão Rural (EMATER). Os demais municípios $(83,06 \%)$ que enviaram resposta ao questionário possuem responsáveis técnicos.

Observa-se, pela Figura 10, que os técnicos agrícolas são a maioria dos responsáveis técnicos contratados pelos municípios. Embora apresentem qualificação, não são habilitados para o cargo, como os engenheiros agrônomos e florestais.

Na opção outros, encontram-se profissionais como: licenciado em ciências agrárias, paisagista, engenheiro civil, zootecnista e biólogo. No entanto, os três últimos, embora tenham sido citados como responsáveis, não possuem embasamento técnico para desempenhar essa função.

A presença do responsável técnico é necessária, uma vez que ele detém o conhecimento de técnicas que possibilitam a produção de mudas com melhor qualidade. No entanto, deve-se ressaltar a importância de estes profissionais estarem sempre se reciclando, a fim de assimilar novas tecnologias e trazer melhoria para a qualidade das mudas. 


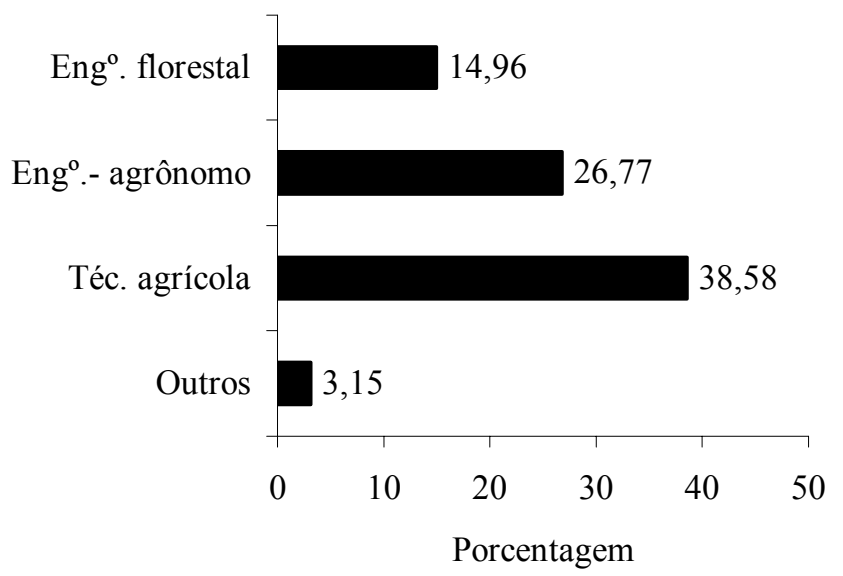

FIGURA 10: Qualificação do responsável técnico nos viveiros dos municípios do Estado de Minas Gerais. FIGURE 10: Competence of the technician responsible for the nurseries of cities of Minas Gerais State.

\section{Perfil dos funcionários}

\section{Treinamento}

Mão-de-obra qualificada e bem treinada é um fator importante para a qualidade do serviço prestado. Assim, um viveiro que tenha esses profissionais é capaz de produzir mudas de melhor qualidade, para qualquer finalidade de uso.

Cerca de $47,79 \%$ dos municípios que enviaram resposta ao item não oferecem treinamento externo aos seus viveiristas, enquanto os 52,21\% restantes o fazem. Alves (2001), em seus estudos sobre o perfil de funcionários que trabalhavam na produção de mudas de eucalipto em uma empresa privada, constatou que $42,69 \%$ dos funcionários recebiam algum tipo de treinamento para exercer a função.

Os principais órgãos que oferecem treinamento para os viveiros municipais são a EMATER $(27,12 \%)$ e o IEF $(40,68 \%)$, seguidos pelo treinamento feito pelo responsável técnico $(25,42 \%)$ e o restante pela EPAMIG, Escolas Agrotécnicas, SENAR, CEMIG, e outros.

\section{Grau de escolaridade}

A escolaridade predominante do viveirista (considerado como o funcionário responsável pelo viveiro) é o $1^{\circ}$ grau incompleto $(37,61 \%)$. Os técnicos agrícolas $\left(2^{\circ}\right.$ grau completo) que também foram considerados como viveiristas corresponderam a $24,77 \%$ dos casos.

Em alguns municípios, até o próprio responsável técnico atuava como viveirista. Para os demais funcionários, o nível de escolaridade predominante (84\%) é o $1^{\circ}$ grau completo e incompleto, o que é uma porcentagem alta se for comparar com o observado por Alves (2001), que foi de 50,6\%. Paula (1997), avaliando o perfil dos funcionários que trabalham na produção de mudas de eucalipto, encontrou grau de escolaridade variando de $1^{\circ}$ grau incompleto a $3^{\circ}$ grau incompleto.

\section{Tempo de exercício na atividade}

A maioria dos viveiristas (54,95\%) exerce a função há mais de cinco anos, mostrando que há baixa rotatividade de funcionários. Os demais possuem tempo de serviço que varia de um mês a cinco anos (45,05\%). Essas porcentagens são maiores do que as encontradas por Alves (2001), que foi de 2,5 anos. Um tempo maior de exercício na atividade pode ser benéfico, uma vez que a experiência dos funcionários tende a refletir diretamente na qualidade das mudas produzidas.

$\mathrm{Na}$ maioria dos municípios, os funcionários são fixos $(87,86 \%)$, o que facilita o processo de treinamento, uma vez que eles só se dedicam a essa atividade. Os demais são contratados temporariamente quando há necessidade ou prestam serviços à prefeitura. 


\section{Média de idade}

A média de idade dos funcionários que trabalham nos viveiros com maior percentual é de 31 a 40 anos $(30,06 \%)$, seguida pela idade de 21 a 30 anos (22,54\%). As classes de 41 a 50 e mais de 50 anos possuem 17,34\% dos funcionários cada uma, os demais encontram-se abaixo de 20 anos. Alves (2001) observou idade média de aproximadamente 34 anos em funcionários que trabalham em viveiros de uma empresa florestal.

\section{Critérios considerados importantes para a expedição de mudas utilizadas na arborização urbana}

A qualidade da muda é, em grande parte, responsável pelo sucesso da implantação da arborização.

Verifica-se pela Figura 11, que o parâmetro considerado mais importante em mudas para arborização urbana (66,93\% dos municípios) é a ausência de doenças, o que é justificável, uma vez que, quando plantadas no meio urbano, deparam-se com uma infinidade de condições adversas. Logo, as mudas precisam estar saudáveis. Outro fator importante, com base em análises, é que 55,91\% dos municípios estão preocupados com a nutrição das plantas.

O tronco reto é também outro parâmetro considerado importante. Isto é justificável, haja vista que a muda torta trará problemas de estabelecimento quando plantada, afetando a estética da arborização.

A altura, considerada uma das características que permitem melhor estabelecimento da muda no meio urbano, só é importante para $41,73 \%$ dos viveiros públicos municipais. Isso demonstra que a maioria deles desconhece as características de qualidade desejáveis para uma muda destinada à arborização urbana.

Observa-se ainda, com base na análise da Figura 11, que não há uma preocupação com todos os parâmetros de qualidade da muda destinada à arborização. Com exceção dos parâmetros já citados, os demais são considerados importantes em menos de $34,65 \%$ das respostas que retornaram. Isso, conseqüentemente, terá reflexos na qualidade da arborização nos municípios.

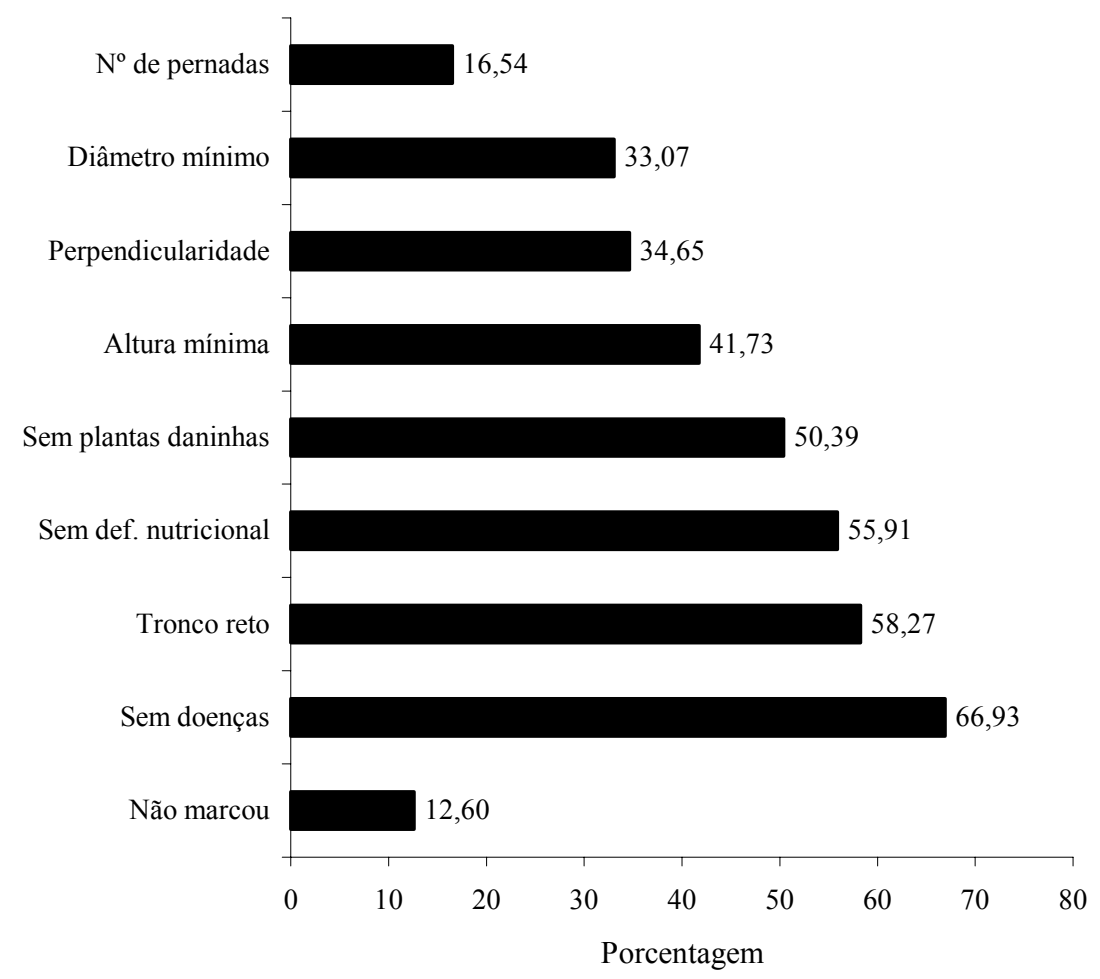

FIGURA 11: Critérios considerados importantes para a expedição de mudas para arborização urbana nos viveiros dos municípios do Estado de Minas Gerais.

FIGURE 11: Criteria considered important for expedition of seedlings for use in urban landscape in the nurseries of the cities of the Minas Gerais State. 


\section{CONCLUSÃO}

O diagnóstico dos viveiros indica que grande parte dos municípios amostrados do Estado de Minas Gerais não possui viveiros para produção de mudas, inferindo-se que estas são adquiridas de terceiros ou não estão sendo plantadas árvores em suas ruas atualmente.

Em relação às condições dos viveiros nos municípios analisados, pode-se concluir que:

- a infra-estrutura é insuficiente e grande parte dos municípios utiliza água de qualidade incerta. Em quase um terço deles, a irrigação é realizada por meio de mangueiras e regadores;

- a maioria dos municípios que possuem viveiros produz mudas para arborização urbana, recuperação de áreas degradadas e matas ciliares, sendo estas destinadas principalmente para doação;

- as mudas são produzidas basicamente por sementes e estacas, não sendo utilizadas técnicas de propagação como estaquia, nem em viveiros que produzem mudas de eucaliptos;

- a porcentagem de municípios que oferecem treinamento aos seus funcionários poderia ser maior, uma vez que estes são em grande parte fixos, embora com baixa escolaridade; e

- em grande parte dos municípios, o conhecimento sobre as características de muda ideal para arborização urbana ainda é incipiente, o que implica que as mudas estão sendo produzidas sem os tratos culturais necessários.

\section{REFERÊNCIAS BIBLIOGRÁFICAS}

ALVES, J.U. Análise ergonômica das atividades de propagação vegetativa de Eucalyptus spp em viveiros. 2001. 94f.Dissertação (Mestrado em Ciência Florestal) - Universidade Federal de Viçosa, Viçosa, 2001.

IBGE - Instituto Brasileiro de Geografia e Estatística. Dados populacionais municipais. Disponível em <http:// www.ibge.gov.br>. Acesso em diversos meses 2002.

IEF- Instituto Estadual de Florestas. Diretoria de desenvolvimento florestal sustentável: viveiros florestais. Disponível em <http:// www.ief.mg.gov.br>. Acesso em 23 out. 2000.

PAIVA, H.N.; GOMES, J.M. Viveiros florestais. 2.ed. Viçosa: UFV, 2000. 69p. (Cadernos didáticos, 72)

PAIVA, H. N.; GONÇALVES, W. Produção de mudas. Viçosa: Aprenda Fácil, 2001. 149p. (Coleção Jardinagem e Paisagismo. Série Arborização Urbana,1).

PAULA, R. A. Metodologia para determinação dos custos da qualidade em produção de mudas de eucalipto. 1997.78f. Dissertação (Mestrado em Ciência Florestal) - Universidade Federal de Viçosa, Viçosa, 1997.

WINTERS,G.H.M.; PERRENOUD, L.A.S.; MOHAMED, E.M.H.M. A arborização urbana em 295 municípios de São Paulo. In: CONGRESSO BRASILEIRO SOBRE ARBORIZAÇÃO URBANA,1., Vitória, 1992. Anais... Vitória: SMMA, 1992. p.175-192. 